\title{
Prémio Ferreira da Silva
}

O Conselho Directivo da Sociedade Portuguesa de Química considerou oportuna uma revisão do regulamento do Prémio Ferreira da Silva (vd. Boletim da $S P Q$ de Janeiro de 1981). Com esta revisão, o prémio passará a distinguir os químicos cuja obra tenha notoriedade e não apenas aqueles cuja actividade se tenha distinguido nos últimos dois anos. Deve, aliás, referir-se que este critério foi já implicitamente considerado na atribuição dos cinco prémios concedidos. Espera-se que as alterações agora introduzidas contribuam para uma melhor definição do perfil de potenciais galardoados e estimulem a apresentação de candidaturas.

\section{Regulamento do Prémio Ferreira da Silva}

$1^{\circ} \mathrm{O}$ prémio "Ferreira da Silva" tem como principal objectivo encorajar e reconhecer a qualidade da investigação científica em Portugal no domínio da Química, em qualquer das suas áreas.

$2^{\circ} \mathrm{O}$ prémio será atribuído bienalmente ao químico português que, pela sua obra ci- entífica produzida em Portugal, tenha contribuído significativamente para o avanço da Química, em qualquer das suas áreas.

$3^{\circ} \mathrm{O}$ prémio consiste numa medalha, em prata, e num diploma assinado pelo Presidente e pelo Secretário Geral da Sociedade.

$4^{\circ}$ A composição do júri, da responsabilidade do Conselho Directivo da Sociedade Portuguesa de Química, é a seguinte: 6,8 ou 10 membros escolhidos de entre os químicos portugueses e sobre os quais haja garantias de capacidade de julgamento e isenção; o Presidente da SPQ, que preside ao júri.

$5^{\circ} \mathrm{O}$ júri deve ser constituído até 30 de Março do ano anterior ao da entrega do prémio.

$6^{\circ} \mathrm{O}$ júri deve considerar os seguintes aspectos:

a) qualidade e quantidade do trabalho de investigação, publicado principalmente nos últimos cinco anos, e seu impacto nas comunidades científicas:

b) criação de escola cientí- fica, avaliada em termos de teses produzidas sob a sua orientação, e de difusão de metodologias de trabalho de carácter experimental ou teóri$\mathrm{co}$;

c) outros aspectos, tais como reconhecimento nacional e internacional, e acções para a divulgação da Química.

$7^{\circ}$ As candidaturas devem ser propostas ao Presidente da SPQ por 5 professores universitários, até 30 de Junho do ano anterior ao da atribuição do prémio. As propostas devem ser acompanhadas de uma justificação e incluir separatas de todos os trabalhos relevantes dos candidatos. As propostas podem também ser feitas em moldes idênticos, por 3 membros do júri.

$8^{\circ} \mathrm{O}$ júri reunirá pelo menos duas vezes entre a sua nomeação e a atribuição do prémio, por convocatória do Presidente da SPQ.

$9^{\circ}$ De cada reunião será lavrada acta; a votação para a distribuição do prémio deve basear-se numa justificação que será lavrada em acta.

$10^{\circ} \mathrm{O}$ júri chegará a uma decisão até 31 de Dezembro do mesmo ano.

$11^{\circ}$ A entrega do prémio será feita na sessão inaugural do Encontro Nacional da SPQ pelo Presidente da Sociedade (ou seu representante), que lerá um pequeno relatório justificativo da decisão do júri.

$12^{\circ} \mathrm{O}$ recipiente do prémio fará parte do júri dos dois prémios seguintes.

$13^{\circ} \mathrm{O}$ recipiente do prémio dará uma lição plenária no Encontro Nacional do ano seguinte àquele em que recebeu o prémio.

$14^{\circ}$ O recipiente de um prémio não é elegível nos dois períodos seguintes àquele em que recebeu o prémio.

$15^{\circ}$ Qualquer dúvida sobre a aplicação deste regulamento será esclarecido pelo Conselho Directivo da SPQ.

$16^{\circ}$ Alterações a este regulamento podem ser feitas pelo Conselho Directivo da SPQ, quer por iniciativa própria, quer por sugestões dos júris ou de membros da Sociedade.

\section{Congressos, Conferências e Reuniões Científicas}

\section{Galileo Galilei \\ Celebrations (EUROCONFERENCE)}

28 th Course: Crystal

Engineering: From

Molecules and Crystals to Materials

12 a 23 Maio de 1999

Erice-Sicily

Informações

Dario Braga

Department of Chemistry

"G. Ciamician"
Via F. Selmi, 2

40126 Bologna, Italy

FAX: 39051259456

TEL: 39051259555

e-mail:

dbraga@ciam.unibo.it

29th Course: Data Mining in Crystallography

12 a 23 Maio de 1999

Erice-Sicily

Informações

Suzanne Fortier
Office of the

Vice-President (Research)

Queen's University

Kingston, K7L 3N6

Canada

FAX: 1613545934

TEL: 1613545933

e-mail:

fortiers@post.queensu.ca
Geral

Curso de Química

Oceanográfica

1 de Janeiro de 1998 a 20

de Maio de 1999

Cádiz, Espanha

Informações

Cursos de Química

Oceanográfica

Centro UNED

Plaza de San António, $\mathrm{n}^{\circ} 3$

11002 Cádiz

FAX: 956-212306 


\section{iLmvac}

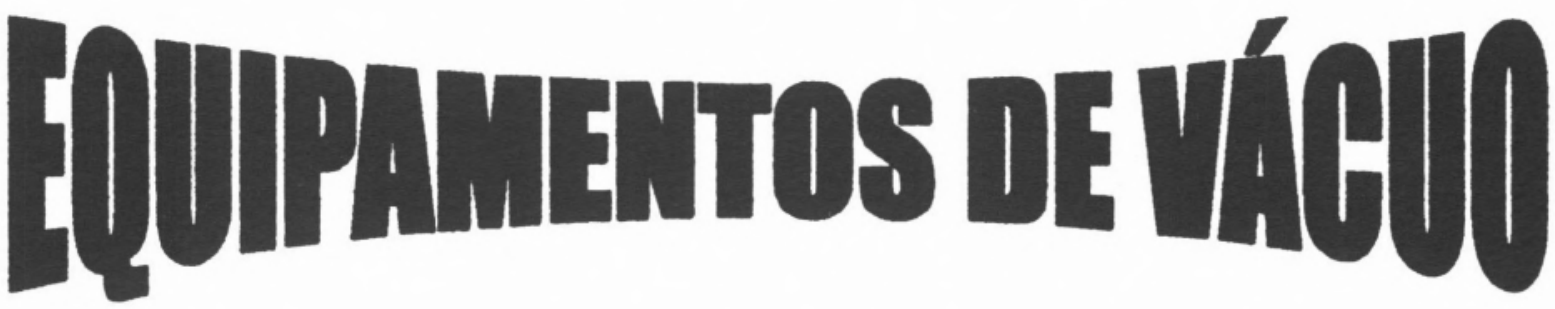

Bombas de Pistão

Bombas de Membrana

Bombas Rotativas de Palhetas

Bombas Difusoras

Bombas Turbomoleculares

Bombas Roots

Bombas Criogénicas

Módulos Químicos com Bomba de Membrana

Módulos de Alto Vácuo Isentos de Óleo

Medidores/Controladores de Vácuo e Pressão de bancada e portáteis: Piezoeléctricos; Pirani; Penning; Capacitivos

Sistemas de Deposição de Filmes Finos

Acessórios; Óleos e "Greases"

Acessórios em Vidro
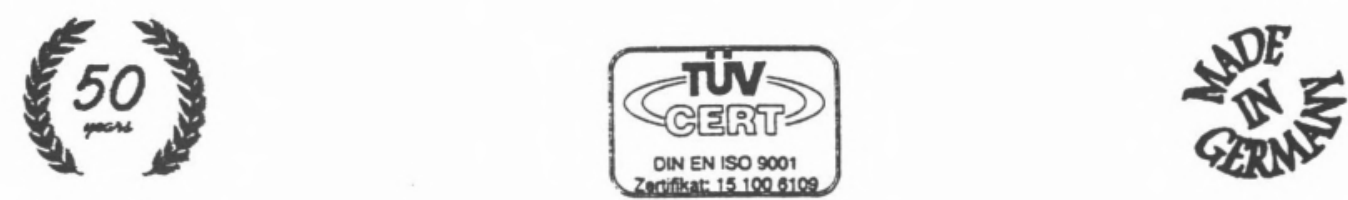

$S Z W$-Equipamentos para a Indústria e Laboratórios, Lda

\section{Representante Exclusivo em Portugal}

Contacte-nos pelo Tel. 01-956 3007 Fax 9562997 E-mail: stv@mail.telepac.pt

Visite-nos: Casal da Serra, lote 103 - loja Esq. 


\section{Campanha de Angariação de Novos Sócios}

A Sociedade Portuguesa de Química (SPQ) é uma sociedade científica sem fins lucrativos que tem por vocação congregar pessoas cuja actividade tem a Química como polo de interesse, apoiando e dinamizando a sua acção nesta área da ciência. Compete à SPQ desenvolver acções com vista à melhoria do ensino da Química no nosso país, nos seus diferentes níveis, promover realizações que interessem aos químicos que trabalham no Ensino, na Investigação e na Indústria. A vitalidade e a dinâmica da SPQ depende fundamentalmente da contribuição da comunidade dos seus associados, através do pagamento das quotas e das suas iniciativas. Neste sentido, a direcção da SPQ apela a todos os seus sócios para que, no seu local de trabalho, levem a cabo uma campanha de informação junto dos seus colegas com o objectivo de divulgar a actividade da nossa Sociedade e de angariar novos sócios.

\section{Vantagens de ser sócio da SPQ:}

- Receber gratuitamente o boletim trimestral Química no qual se publicam artigos de interesse para os químicos e se divulga informação sobre as acções desenvolvidas pela SPQ nas suas áreas de intervenção.

- Beneficiar de descontos nas inscrições nos Encontros promovidos e apoiados pela Sociedade.

- Beneficiar de descontos na aquisição de publicações da SPQ.

- Ter acesso à Biblioteca e ao software didáctico da SPQ.

\section{Benefícios concedidos aos novos sócios:}

Desconto de $500 \$ 00$ na 1a quota e desconto de $5 \%$ em todas as publicações da SPQ se forem adquiridas durante o primeiro ano de inscrição.

Como reconhecimento aos sócios que colaborem de forma mais activa nesta campanha de angariação, àqueles que tiverem angariado três ou mais novos sócios, a SPQ oferece um exemplar de uma das serigrafias sobre Locais Históricos da Química em Portugal recentemente produzidas pela Sociedade. Para tal, o sócio proponente, devidamente identificado, deverá enviar para a sede da SPQ os Boletins de inscrição (e respectivos cheques) dos sócios angariados.

Esta campanha estará em vigor até 31 de Dezembro de 1998. 
Av da República, $\mathrm{n}^{0} 37,4^{\circ}$ - 1050 LISBOA

Tel. (01)7934637 Fax(01)7952349

Contribuinte $\mathrm{n}^{\circ} 501139265$

Sociedade sem fins lucrativos

Diário República n$^{\circ} 226$ de 29.9.1994, III série
Tipo de Sócio

Sócio Efectivo: $5.500 \$ 00$

Sócio Estudante: $3.000 \$ 00$

Sócio Casal: $8.500 \$ 00$

\section{Ficha de Inscrição de um Novo Sócio}

\section{Sócio $\mathrm{N}^{\circ}$}

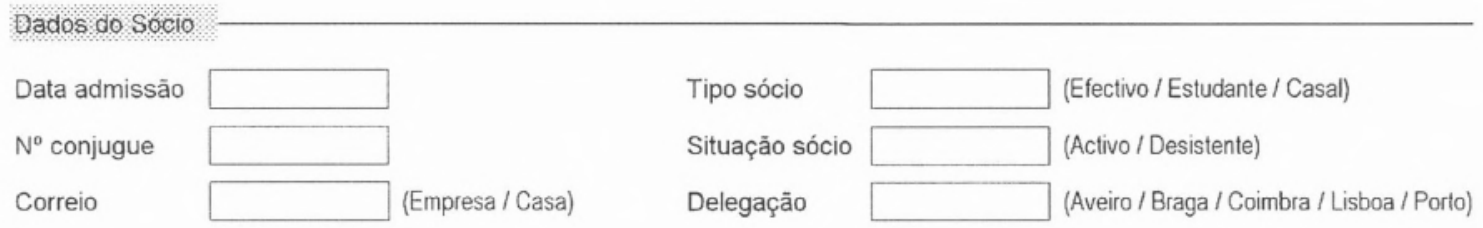

Dadas do Socio

Nome

Morada

Cód. postal

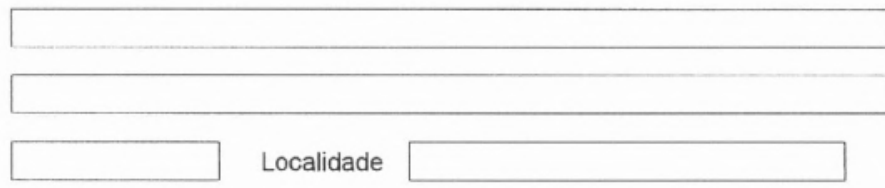

Data nasc.

Telefone

País

Habilitacoues e Profissáo

Habilitaçōes/

Instituiçāo/Ano

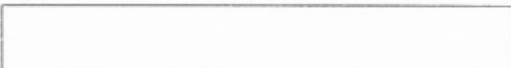

Profissāo

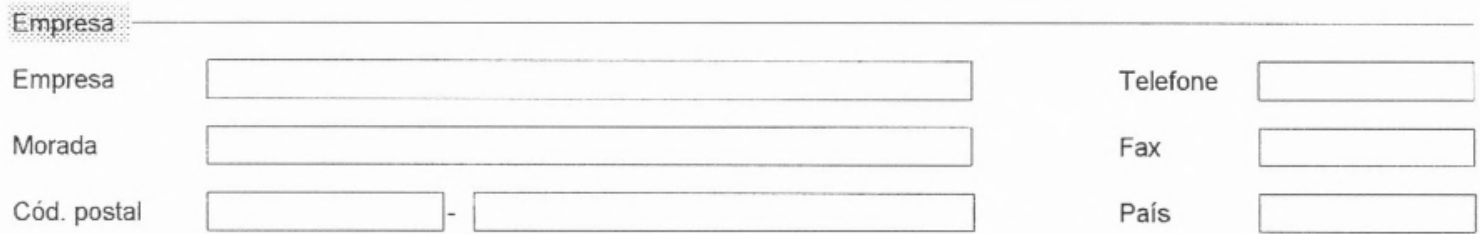

Divisōes/Grupos ()

$\begin{array}{lll}\square 1 & \text { D1 } & \text { Divisão 1: Catálise } \\ \square 2 & \text { D2 } & \text { Divisão 2: Educação } \\ \square 3 & \text { D3 } & \text { Divisão 3: Química Analitica } \\ \square 4 & \text { D4 } & \text { Divisão 4: Química-Física } \\ \square 5 & \text { D5 } & \text { Divisão 5: Química Industrial } \\ \square 6 & \text { D6 } & \text { Divisão 6: Química Inorgânica } \\ \square 7 & \text { D7 } & \text { Divisão 7: Quimica Orgânica } \\ \square 8 & \text { G1 } & \text { Grupo 1: Computadores em Química } \\ \square 9 & \text { G2 } & \text { Grupo 2: Espectrometria de Massa } \\ \square 10 & \text { G3 } & \text { Grupo 3: Quimica Alimentar } \\ \square 11 & \text { G4 } & \text { Grupo 4: Radicais Livres } \\ \square 12 & \text { G5 } & \text { Grupo 5: Quimica dos Glucidos } \\ \square 13 & \text { Go/D0 } & \text { Divisão e Grupo Desconhecidos }\end{array}$

Pagamento da Quota de 1998

$\begin{aligned} & \text { Junto envio o cheque/vale postal } n^{0} \\ & \text { Banco/CTT no valor de } \\ & \text { ordem da Sociedade Portuguesa de Química. }\end{aligned}$
Assinatura

